\title{
Comparative efficacy and safety of adjuvant nivolumab versus other treatments in adults with resected melanoma: a systematic literature review and network meta-analysis
}

Kabirraaj Toor ${ }^{1 *}$, Mark R. Middleton ${ }^{2}$, Keith Chan ${ }^{1}$, Adenike Amadi ${ }^{3}$, Andriy Moshyk $^{4}$ and Srividya Kotapati ${ }^{4}$

\begin{abstract}
Background: Immune checkpoint inhibitors and targeted therapies are approved for adjuvant treatment of patients with resected melanoma; however, they have not been compared in randomized controlled trials (RCTs). We compared the efficacy and safety of adjuvant nivolumab with other approved treatments using available evidence from RCTs in a Bayesian network meta-analysis (NMA).

Methods: A systematic literature review was conducted through May 2019 to identify relevant RCTs evaluating approved adjuvant treatments. Outcomes of interest included recurrence-free survival (RFS)/disease-free survival (DFS), distant metastasis-free survival (DMFS), all-cause grade 3/4 adverse events (AEs), discontinuations, and discontinuations due to AEs. Time-to-event outcomes (RFS/DFS and DMFS) were analyzed both assuming that hazard ratios (HRs) are constant over time and that they vary.

Results: Of 26 identified RCTs, 19 were included in the NMA following a feasibility assessment. Based on HRs for RFS/ DFS, the risk of recurrence with nivolumab was similar to that of pembrolizumab and lower than that of ipilimumab $3 \mathrm{mg} / \mathrm{kg}$, ipilimumab $10 \mathrm{mg} / \mathrm{kg}$, or interferon. Risk of recurrence with nivolumab was similar to that of dabrafenib plus trametinib at 12 months, however, was lower beyond 12 months (HR [95\% credible interval] at 24 months, 0.46 [0.270.78]; at 36 months, 0.28 [0.14-0.59]). Based on HRs for DMFS, the risk of developing distant metastases was lower with nivolumab than with ipilimumab $10 \mathrm{mg} / \mathrm{kg}$ or interferon and was similar to dabrafenib plus trametinib.
\end{abstract}

Conclusion: Adjuvant therapy with nivolumab provides an effective treatment option with a promising risk-benefit profile. Keywords: Adjuvant treatment, Systematic literature review, Network meta-analysis, Nivolumab, Efficacy, Safety

\footnotetext{
* Correspondence: kabirraaj.toor@precisionvh.com

${ }^{1}$ Precision HEOR, 1505 West 2nd Avenue, Vancouver, BC V6H 3Y4, Canada

Full list of author information is available at the end of the article
}

(c) The Author(s). 2021 Open Access This article is licensed under a Creative Commons Attribution 4.0 International License, which permits use, sharing, adaptation, distribution and reproduction in any medium or format, as long as you give appropriate credit to the original author(s) and the source, provide a link to the Creative Commons licence, and indicate if changes were made. The images or other third party material in this article are included in the article's Creative Commons licence, unless indicated otherwise in a credit line to the material. If material is not included in the article's Creative Commons licence and your intended use is not permitted by statutory regulation or exceeds the permitted use, you will need to obtain permission directly from the copyright holder. To view a copy of this licence, visit http://creativecommons.org/licenses/by/4.0/. The Creative Commons Public Domain Dedication waiver (http://creativecommons.org/publicdomain/zero/1.0/) applies to the data made available in this article, unless otherwise stated in a credit line to the data. 


\section{Background}

The incidence of melanoma, a type of skin cancer that develops from melanocytes, has consistently increased worldwide [1, 2]. In 2009 , more than 850,000 people in the United States had a history of melanoma [2, 3]. Melanoma is surgically treated with curative intent if diagnosed at an early stage; however, once melanoma metastasizes, treatment with curative intent is not an option [1]. In patients with resected melanoma, clinically important outcomes include recurrence-free survival (RFS)/diseasefree survival (DFS), which measures the curative efficacy of treatment, and distant metastasis-free survival (DMFS), which measures the curative efficacy of treatment in preventing advanced or metastatic disease [4].

Traditionally, patients with intermediate-risk (stages II and IIIA) and high-risk (stage IIIB, stage IIIC, and resectable stage IV) melanoma have been treated with regional radiotherapy and immunostimulants, in addition to watchful waiting after surgery (adjuvant setting) $[2,5,6]$. Without active treatment, only 55 to $60 \%$ of patients remain recurrence-free at 1 year [7-9]. Since 2011, adjuvant treatment options have expanded to include biologic agents such as interferon (IFN)-alpha and immune checkpoint inhibitors, such as cytotoxic T-lymphocyte antigen 4 and programmed death (PD)-1 inhibitors [1, 2]. IFN-alpha was the first agent to demonstrate RFS/DFS benefit in a randomized controlled trial (RCT) [2, 10]. Additionally, three immune checkpoint inhibitors (ipilimumab, nivolumab, and pembrolizumab), as well as the BRAF/MEK inhibitor combination dabrafenib plus trametinib, have been approved by the US Food and Drug Administration (FDA) for the adjuvant treatment of patients with melanoma [11-14]. Most of the trials involving these agents utilized placebo rather than an active comparator as the control and reported that 70 to $88 \%$ of patients remained recurrence-free 1 year after initiating active adjuvant treatment [7-9]. Although ipilimumab $10 \mathrm{mg} / \mathrm{kg}$ and nivolumab $3 \mathrm{mg} / \mathrm{kg}$ have been compared head to head in the phase III CheckMate 238 trial [15], efficacy and safety comparisons between nivolumab and other adjuvant treatments in clinical trials are lacking.

Network meta-analysis (NMA) is a statistical method that allows indirect comparisons between treatments when head-to-head evidence is not available and naive comparisons would be prone to selection bias and imbalance in a variety of baseline characteristics. Specifically, NMA can be used to combine direct and indirect evidence for any interventions that form a network of RCTs in which each trial has at least one intervention (active or placebo) in common with another trial and all trials are sufficiently similar [16, 17]. Furthermore, NMA is based on the analysis of relative treatment effects rather than a comparison of absolute values of efficacy outcomes. Two NMAs on adjuvant treatment options in melanoma were published recently [18, 19]. One of these studies reported treatment effects with an assumption of proportional hazards (i.e., a constant hazard ratio [HR]) in comparing the safety of dabrafenib plus trametinib with other adjuvant therapies, including nivolumab [18]. The other study allowed for time-varying treatment effect when comparing pembrolizumab with adjuvant therapies other than nivolumab and did not present a safety analysis [19]. The current study was conducted using publicly available evidence from RCTs identified through a systematic literature review (SLR), which was then synthesized by means of an NMA to assess the efficacy and safety of nivolumab versus other treatment options in patients with resected melanoma by using both constant and time-varying treatment-effect assumptions.

\section{Methods}

Literature search

Our SLR included RCTs that reported the comparative efficacy and safety of pharmacologic interventions for the adjuvant treatment of patients with resected melanoma in terms of RFS/DFS, DMFS, all-cause grade 3/4 adverse events (AEs), discontinuations, and discontinuations due to AEs. Studies in patients with stage III/IV melanoma published through May 2019 were included; studies assessing patients with stage II melanoma were also included if this population was assessed in addition to the stage III/IV population. To assess the impact of studies assessing stage II melanoma patients, a subgroup (sensitivity) analysis was conducted in studies that included only patients with resectable stage III/IV melanoma or reported stage III/IV subgroup data. The quality of individual trials was assessed using the Cochrane risk-of-bias tool. Full details and results of the SLR are provided in Additional file 1: Appendix A.

A feasibility assessment was conducted to gauge the appropriateness of proceeding with an NMA. This process included the following steps: (1) determination of whether the RCT formed a single evidence network for each outcome of interest (RFS/DFS, DMFS, grade 3/4 AEs, discontinuations, and discontinuations due to AEs) and (2) assessment of the distribution of treatment, outcomes, study, and patient characteristics that affected treatment effects across direct comparisons of the evidence networks when head-to-head evidence existed. Network meta-analyses were conducted in a Bayesian framework for the RCTs identified in the SLR that formed part of a single evidence network and were deemed sufficiently similar for each population and outcome of interest. Consistency between direct and indirect estimates was evaluated for closed loops (see Additional file 2: Appendix B for results of consistency checks). For binary outcomes, such as grade 3/4 AEs, discontinuations, and discontinuations due to AEs, NMAs were performed based on the proportion of patients experiencing the event of interest using a regression model with a binomial likelihood and logit link. 
For survival outcomes, specifically RFS/DFS and DMFS (reported either as HRs or Kaplan-Meier [KM] curves), NMAs were conducted based either on the assumption that HRs remained constant over time or that HRs varied over time. In a typical survival analysis, the ratio of the risk of an event occurring between two treatments was assumed to be constant over time (ie, proportional hazards assumption); however, this assumption did not hold for some comparative survival analyses, evidenced by overlapping KM curves or based on the results of the Grambsch and Therneau test. In such cases, an additional analysis that allowed for time-varying HRs was conducted using methods described previously [20, 21]. For these methods, the hazard functions of the interventions in a trial were modeled using known survival functions (such as Weibull or Gompertz, generally referred to as fractional polynomials), and differences in the parameters were considered in the multidimensional treatment effects, which were synthesized and indirectly compared across studies in the NMA. Because of this approach, treatment effects were represented by multiple parameters, rather than a single parameter. In this study, the model introduced by Jansen [20] was used for NMAs of RFS/DFS and DMFS. Normal non-informative prior distributions were used for all parameters (mean of 0; variance of 10,000). Relative treatment effects were expressed as HRs for RFS/DFS and DMFS and odds ratios for AEs and discontinuations, with 95\% credible intervals (CrIs).

\section{Results}

\section{Evidence base}

An SLR conducted through May 2019 identified 11 new studies in addition to the 41 studies identified in an earlier SLR, generating an evidence base of 52 studies (Additional file 1: Appendix A, Fig. A.1). These studies represent 26 RCTs. A feasibility assessment excluded seven trials, comprising two trials that assessed only patients with mucosal melanoma, two that included patients with stage I disease and did not provide data for the stage III/IV disease subgroup, one that pooled ipilimumab dosing groups, and two that were treated as single-arm trials due to aggregation of nodes (interventions of interest). Overall, 19 trials were included in the NMA. Among these trials, IFN was the most frequently assessed treatment $(n=13)$, followed by other chemotherapy $(n=4)$, and ipilimumab $10 \mathrm{mg} / \mathrm{kg}(n=3)$. Ipilimumab $3 \mathrm{mg} / \mathrm{kg}$, nivolumab, pembrolizumab, and dabrafenib plus trametinib were assessed in one trial each. The analysis of RFS/DFS included 18 trials assessing eight treatments (Fig. 1a), and the analysis of DMFS included five trials assessing five treatments (Fig. 1b).

Characteristics of the 26 RCTs included in the feasibility assessment for the NMA are provided in Table $1[7,10,15$, 22-47]. The treatments included in this analysis were consistent across the network because the eligibility criteria for the interventions were restricted primarily to FDAapproved doses. Although ipilimumab $3 \mathrm{mg} / \mathrm{kg}$ and $10 \mathrm{mg} / \mathrm{kg}$ were used for the treatment of patients with resected melanoma in the studies included in this NMA, only the $10-\mathrm{mg} / \mathrm{kg}$ dose is approved in the adjuvant setting. The observation/placebo and other-chemotherapy nodes consisted of more than one treatment type. Among the 19 trials included in the observation/placebo node, observation was the control in 16 trials and placebo served as the control in three trials. In the other-chemotherapy node, four of the five chemotherapies were either dacarbazine or IFN; however, the treatment regimens were different.

Baseline patient characteristics were largely similar across the trials, including age and race (Additional file 1: Appendix A, Table A.11). However, differences in patient characteristics were observed in American Joint Committee on Cancer stage and BRAF mutation status at baseline. To assess whether differences in patient characteristics had an effect on the analysis, a subgroup analysis was conducted in patients with stage III/IV disease. However, a lack of available data and network connectivity precluded a subgroup analysis based on $B R A F$ status, as only three trials reported this information.

\section{Efficacy}

Based on HRs for RFS/DFS, the risk of recurrence was similar between nivolumab and dabrafenib plus trametinib (HR 1.06, CrI 0.77-1.45) and between nivolumab and pembrolizumab (HR 0.92, CrI 0.67-1.29) when the HR was constant over time (Table 2). Risk of recurrence was lower with nivolumab than with ipilimumab $3 \mathrm{mg} / \mathrm{kg}$, ipilimumab $10 \mathrm{mg} / \mathrm{kg}$, or IFN. As the assumption of proportional hazards did not hold, a subsequent analysis was conducted in which $\mathrm{HR}$ varied over time. In this analysis, the risk of recurrence with nivolumab was similar to that with dabrafenib plus trametinib at 12 months (HR 1.02, 95\% CrI 0.71-1.47), but was lower at later time points (HR at 24 months 0.46, 95\% CrI 0.27-0.78; HR at 36 months 0.28 , 95\% CrI 0.14-0.59) (Table 3).

Based on HRs for DMFS, the risk of developing distant metastases was lower with nivolumab than with ipilimumab $10 \mathrm{mg} / \mathrm{kg}$ or IFN but was similar to that of dabrafenib plus trametinib (Table 4). In the analysis with time-varying $\mathrm{HR}$, the risk of developing distant metastases was lower for nivolumab compared with observation/placebo at 12 months (HR 0.67, 95\% CrI 0.48-0.93), but was not different at later time points or compared with other treatments (Table 5). Pembrolizumab was not included in the DMFS analysis due to a lack of publicly available data. Results for RFS/DFS and DMFS were consistent between subgroup analyses that included patients with stage III/IV 


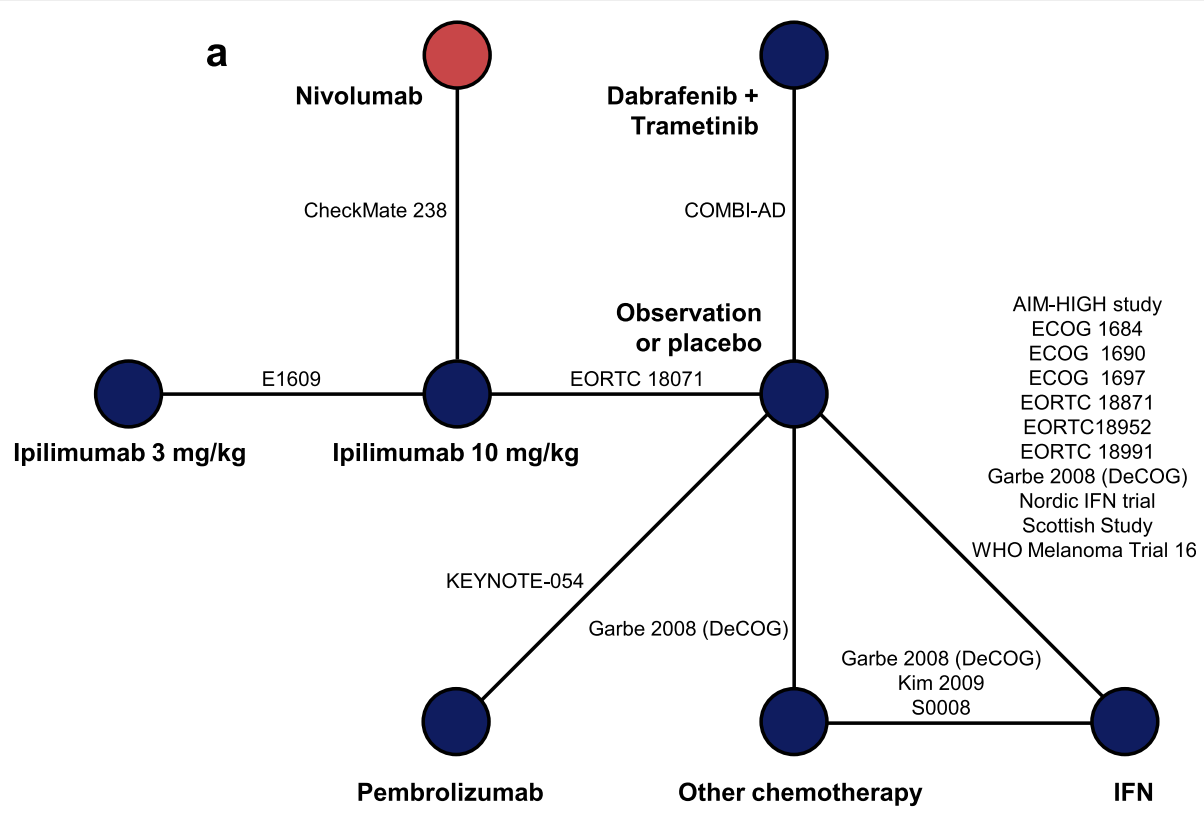

b

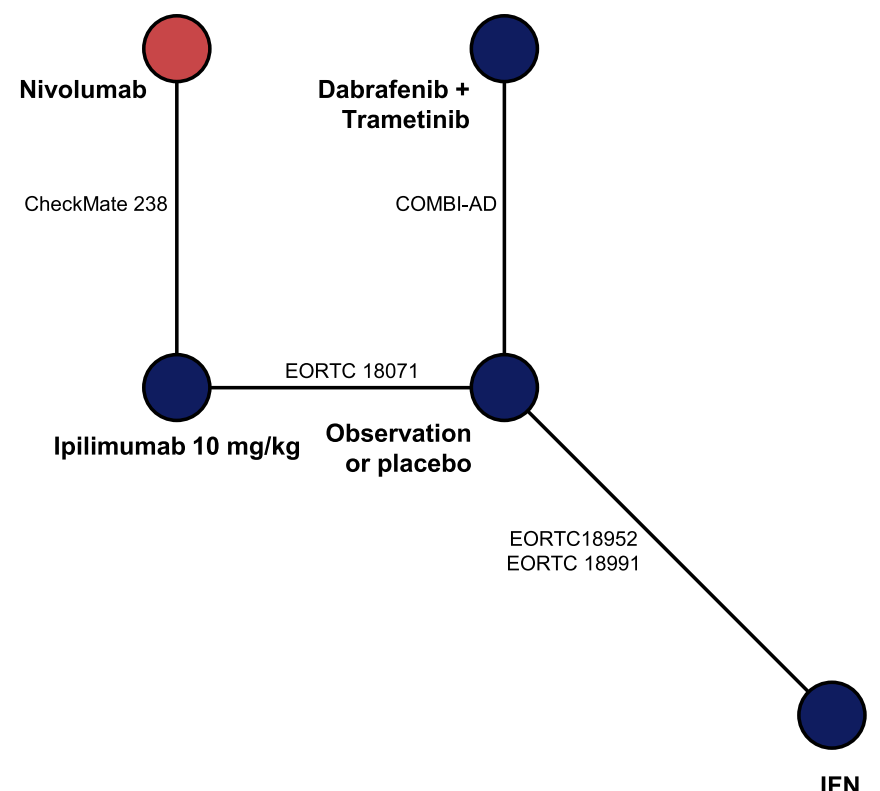

Fig. 1 Network diagrams of randomized controlled trials for base-case efficacy outcomes in patients with stage II-IV melanoma for a RFS/DFS and $\mathbf{b}$ DMFS. DFS disease-free survival, DMFS distant metastasis-free survival, IFN interferon, RFS recurrence-free survival

disease and overall analyses that included patients with stage II-IV disease (see Additional file 3: Appendix C).

\section{Safety}

Based on odds ratios estimated in the safety analyses, nivolumab was associated with lower rates of grade $3 / 4$ AEs than the other active interventions (Additional file 4: Appendix D, Table D.1) and lower rates of discontinuations due to AEs than the other active interventions, with the exception of pembrolizumab (Additional file 4:
Appendix D, Table D.2). Overall discontinuation rates with nivolumab were lower than those with ipilimumab $10 \mathrm{mg} / \mathrm{kg}$ or IFN and similar to those with the other treatment options (Additional file 4: Appendix D, Table D.3). Detailed results of the safety analyses are presented in Additional file 4: Appendix D.

\section{Discussion}

This study assessed clinical outcomes with adjuvant nivolumab compared with other treatment options in 


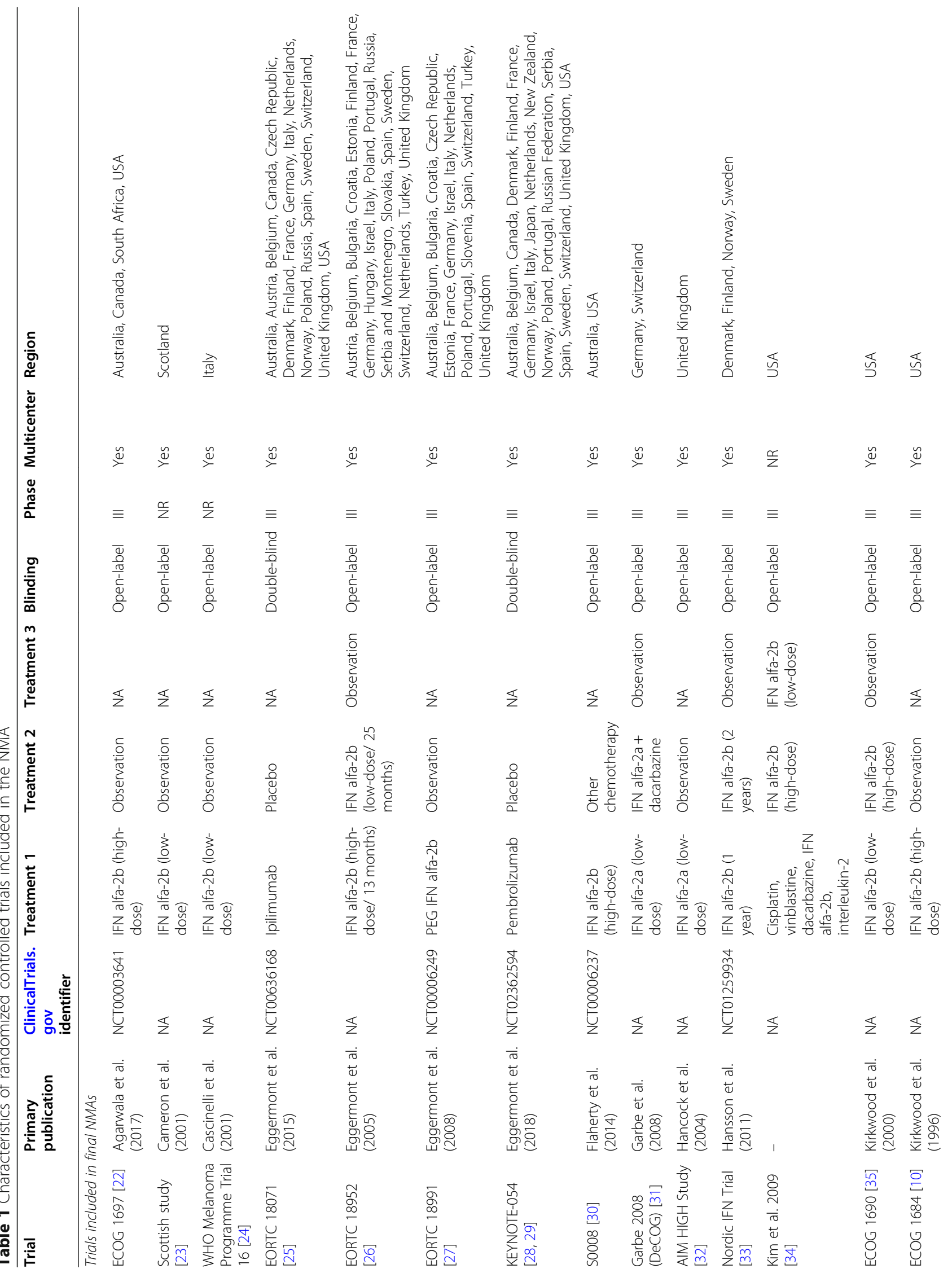




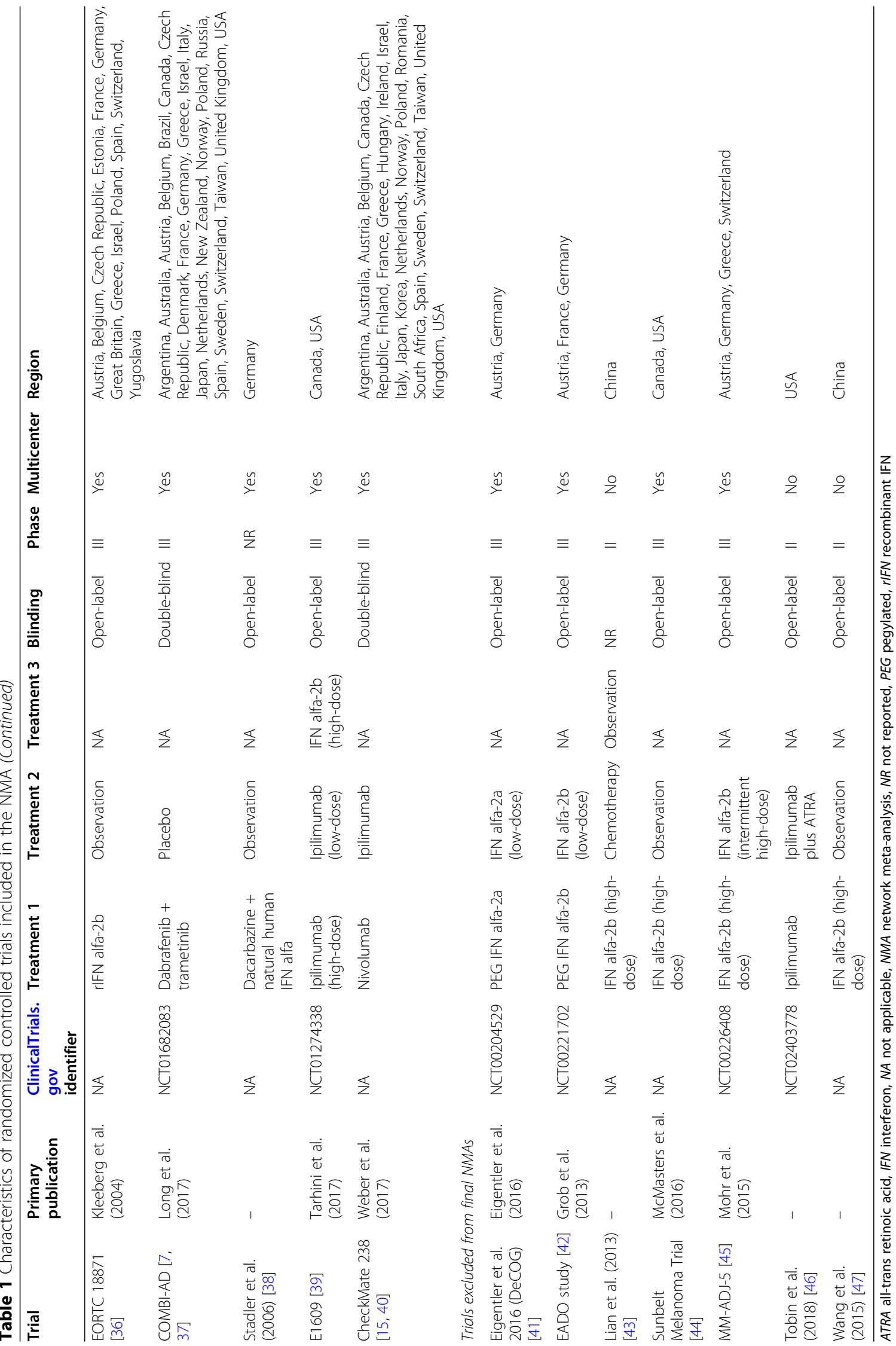


Table 2 Constant HR estimates ${ }^{a}$ from a fixed-effects NMA of RFS/DFS in patients with resected stage II-IV melanoma

\begin{tabular}{|c|c|c|c|c|c|c|c|}
\hline $\begin{array}{c}\text { Observation or } \\
\text { placebo }\end{array}$ & $\begin{array}{c}1.93 \\
(1.50-2.48)\end{array}$ & $\begin{array}{c}2.04 \\
(1.68-2.48)\end{array}$ & $\begin{array}{c}1.79 \\
(1.45-2.20)\end{array}$ & $\begin{array}{c}1.32 \\
(1.11-1.55)\end{array}$ & $\begin{array}{c}1.32 \\
(1.00-1.73)\end{array}$ & $\begin{array}{c}1.17 \\
(0.97-1.41)\end{array}$ & $\begin{array}{c}1.13 \\
(1.06-1.21)\end{array}$ \\
\hline $\begin{array}{c}0.52 \\
(0.40-0.67)\end{array}$ & Nivolumab & $\begin{array}{c}1.06 \\
(0.77-1.45)\end{array}$ & $\begin{array}{c}0.92 \\
(0.67-1.29)\end{array}$ & $\begin{array}{c}0.68 \\
(0.56-0.82)\end{array}$ & $\begin{array}{c}0.68 \\
(0.51-0.90)\end{array}$ & $\begin{array}{c}0.61 \\
(0.44-0.83)\end{array}$ & $\begin{array}{c}0.59 \\
(0.45-0.76)\end{array}$ \\
\hline $\begin{array}{c}0.49 \\
(0.40-0.59)\end{array}$ & $\begin{array}{c}0.95 \\
(0.69-1.30)\end{array}$ & $\begin{array}{c}\text { Dabrafenib + } \\
\text { trametinib }\end{array}$ & $\begin{array}{c}0.88 \\
(0.66-1.17)\end{array}$ & $\begin{array}{c}0.64 \\
(0.50-0.83)\end{array}$ & $\begin{array}{c}0.64 \\
(0.46-0.91)\end{array}$ & $\begin{array}{c}0.58 \\
(0.44-0.75)\end{array}$ & $\begin{array}{c}0.55 \\
(0.45-0.68)\end{array}$ \\
\hline $\begin{array}{c}0.56 \\
(0.45-0.69)\end{array}$ & $\begin{array}{c}1.08 \\
(0.78-1.49)\end{array}$ & $\begin{array}{c}1.14 \\
(0.86-1.52)\end{array}$ & Pembrolizumab & $\begin{array}{c}0.74 \\
(0.56-0.95)\end{array}$ & $\begin{array}{c}0.73 \\
(0.52-1.03)\end{array}$ & $\begin{array}{c}0.66 \\
(0.49-0.87)\end{array}$ & $\begin{array}{c}0.63 \\
(0.51-0.79)\end{array}$ \\
\hline $\begin{array}{c}0.76 \\
(0.65-0.90)\end{array}$ & $\begin{array}{c}1.47 \\
(1.22-1.78)\end{array}$ & $\begin{array}{c}1.55 \\
(1.20-2.01)\end{array}$ & $\begin{array}{c}1.36 \\
(1.05-1.77)\end{array}$ & $\begin{array}{l}\text { Ipilimumab } \\
10 \mathrm{mg} / \mathrm{kg}\end{array}$ & $\begin{array}{c}1.00 \\
(0.81-1.24)\end{array}$ & $\begin{array}{c}0.89 \\
(0.70-1.15)\end{array}$ & $\begin{array}{c}0.86 \\
(0.72-1.03)\end{array}$ \\
\hline $\begin{array}{c}0.76 \\
(0.58-1.00)\end{array}$ & $\begin{array}{c}1.47 \\
(1.11-1.95)\end{array}$ & $\begin{array}{c}1.55 \\
(1.10-2.19)\end{array}$ & $\begin{array}{c}1.36 \\
(0.97-1.92)\end{array}$ & $\begin{array}{c}1.00 \\
(0.81-1.24)\end{array}$ & $\begin{array}{c}\text { Ipilimumab } 3 \\
\mathrm{mg} / \mathrm{kg}\end{array}$ & $\begin{array}{c}0.89 \\
(0.64-1.25)\end{array}$ & $\begin{array}{c}0.86 \\
(0.65-1.15)\end{array}$ \\
\hline $\begin{array}{c}0.85 \\
(0.71-1.03)\end{array}$ & $\begin{array}{c}1.65 \\
(1.20-2.25)\end{array}$ & $\begin{array}{c}1.74 \\
(1.33-2.30)\end{array}$ & $\begin{array}{c}1.53 \\
(1.15-2.03)\end{array}$ & $\begin{array}{c}1.12 \\
(0.87-1.44)\end{array}$ & $\begin{array}{c}1.12 \\
(0.80-1.57)\end{array}$ & $\begin{array}{c}\text { Other } \\
\text { chemotherapy }\end{array}$ & $\begin{array}{c}0.97 \\
(0.81-1.16)\end{array}$ \\
\hline $\begin{array}{c}0.88 \\
(0.83-0.94)\end{array}$ & $\begin{array}{c}1.70 \\
(1.32-2.21)\end{array}$ & $\begin{array}{c}1.80 \\
(1.47-2.21)\end{array}$ & $\begin{array}{c}1.58 \\
(1.27-1.96)\end{array}$ & $\begin{array}{c}1.16 \\
(0.97-1.38)\end{array}$ & $\begin{array}{c}1.16 \\
(0.87-1.54)\end{array}$ & $\begin{array}{c}1.04 \\
(0.86-1.24)\end{array}$ & IFN pooled \\
\hline
\end{tabular}

${ }^{a}$ The value in each cell represents the hazard ratio (95\% credible interval) for the comparison of the treatment indicated in that row versus the treatment indicated in that column; bolded values are statistically significant at the 0.05 significance level

DFS disease-free survival, HR hazard ratio, IFN interferon, NMA network meta-analysis, RFS recurrence-free survival

patients with resected melanoma. In this NMA, nivolumab was associated with a reduction in the risk of recurrence or death compared with observation/placebo, ipilimumab, or historical treatments such as IFN or chemotherapy. The risk of recurrence was significantly lower with nivolumab than dabrafenib plus trametinib at 24 months and beyond. In addition, the risk of developing distant metastases was significantly lower with nivolumab than observation/placebo, ipilimumab, or IFN. A comparison between nivolumab and pembrolizumab did not show any differences in the risk of recurrence or distant metastases.
The limitations associated with the source of data and methods used in indirect treatment comparisons should be considered in interpreting these findings. Inherent to all SLRs is the risk of missing relevant articles due to publication after the search date, improper cataloguing within databases, and publication in non-academic literature. These limitations were mitigated by using a broad search strategy among three major databases and conducting individual searches of relevant conference proceedings.

The feasibility assessment that was conducted to explore heterogeneity in terms of trial, patient, treatment,

Table 3 Time-varying HR estimates ${ }^{a}$ from a fixed-effects NMA of RFS/DFS ( $p 1=0, p 2=-1$, scale, shape $\times 1$ ) in patients with resected stage II-IV melanoma

\begin{tabular}{|c|c|c|c|c|}
\hline \multirow[t]{2}{*}{ Treatment } & \multicolumn{4}{|l|}{ Time points } \\
\hline & 12 months & 24 months & 36 months & 48 months \\
\hline NIVO vs. OBS/PBO & $0.58(0.43-0.77)$ & $0.51(0.33-0.80)$ & $0.46(0.26-0.86)$ & $0.43(0.21-0.91)$ \\
\hline NIVO vs. DAB+TRAM & $1.02(0.71-1.47)$ & $0.46(0.27-0.78)$ & $0.28(0.14-0.59)$ & $0.20(0.08-0.49)$ \\
\hline NIVO vs. PEM & $1.19(0.81-1.76)$ & $1.06(0.56-2.05)$ & $0.96(0.40-2.29)$ & $0.88(0.30-2.51)$ \\
\hline NIVO vs. IPI (10 mg/kg) & $0.69(0.55-0.86)$ & $0.66(0.46-0.96)$ & $0.65(0.40-1.07)$ & $0.64(0.35-1.17)$ \\
\hline NIVO vs. IPI (3 mg/kg) & $0.75(0.54-1.04)$ & $0.93(0.58-1.48)$ & $1.06(0.57-2.01)$ & $1.16(0.54-2.55)$ \\
\hline NIVO vs. CHEM & $0.63(0.44-0.89)$ & $0.53(0.32-0.86)$ & $0.47(0.24-0.91)$ & $0.42(0.19-0.95)$ \\
\hline NIVO vs. IFN & $0.64(0.48-0.86)$ & $0.55(0.36-0.88)$ & $0.49(0.27-0.93)$ & $0.46(0.22-0.97)$ \\
\hline
\end{tabular}

${ }^{a}$ The value in each cell represents the hazard ratio ( $95 \%$ credible interval) for the comparison of the treatments; bolded values are statistically significant at the 0.05 significance level

CHEM other chemotherapy, DAB dabrafenib, DFS disease-free survival, HR hazard ratio, IFN interferon, IPI ipilimumab, NIVO nivolumab, NMA network meta-analysis, $O B S$ observation, $P B O$ placebo, $P E M$ pembrolizumab, RFS recurrence-free survival, TRAM trametinib 
Table 4 Constant HR estimates ${ }^{a}$ from a fixed-effects NMA of DMFS in patients with stage II-IV melanoma

\begin{tabular}{|c|c|c|c|c|}
\hline $\begin{array}{l}\text { Observation or } \\
\text { placebo }\end{array}$ & $\begin{array}{c}1.69 \\
(1.25-2.25)\end{array}$ & $\begin{array}{c}1.89 \\
(1.50-2.39)\end{array}$ & $\begin{array}{c}1.32 \\
(1.10-1.57)\end{array}$ & $\begin{array}{c}1.09 \\
(0.98-1.22)\end{array}$ \\
\hline $\begin{array}{c}0.59 \\
(0.44-0.80)\end{array}$ & Nivolumab & $\begin{array}{c}1.12 \\
(0.77-1.62)\end{array}$ & $\begin{array}{c}0.78 \\
(0.62-0.99)\end{array}$ & $\begin{array}{c}0.64 \\
(0.47-0.88)\end{array}$ \\
\hline $\begin{array}{c}0.53 \\
(0.42-0.67)\end{array}$ & $\begin{array}{c}0.89 \\
(0.62-1.29)\end{array}$ & $\begin{array}{c}\text { Dabrafenib + } \\
\text { trametinib }\end{array}$ & $\begin{array}{c}0.70 \\
(0.53-0.93)\end{array}$ & $\begin{array}{c}0.58 \\
(0.44-0.75)\end{array}$ \\
\hline $\begin{array}{c}0.76 \\
(0.64-0.91)\end{array}$ & $\begin{array}{c}1.28 \\
(1.01-1.62)\end{array}$ & $\begin{array}{c}1.44 \\
(1.08-1.90)\end{array}$ & $\begin{array}{l}\text { Ipilimumab } \\
10 \text { mg/kg }\end{array}$ & $\begin{array}{c}0.83 \\
(0.68-1.02)\end{array}$ \\
\hline $\begin{array}{c}0.92 \\
(0.82-1.02)\end{array}$ & $\begin{array}{c}1.55 \\
(1.13-2.11)\end{array}$ & $\begin{array}{c}1.73 \\
(1.34-2.26)\end{array}$ & $\begin{array}{c}1.21 \\
(0.98-1.48)\end{array}$ & IFN pooled \\
\hline
\end{tabular}

${ }^{a}$ The value in each cell represents the hazard ratio ( $95 \%$ credible interval) for the comparison of the treatment indicated in that row versus the treatment indicated in that column; bolded values are statistically significant at the 0.05 significance level $H R$ hazard ratio, DMFS distant metastasis-free survival, IFN interferon, NMA network meta-analysis

and outcome characteristics identified some important differences between the treatments [16]. However, the current analysis assumed that the type of therapies in the other-chemotherapy group or the observation/placebo group did not act as a treatment-effect modifier. In addition, this study assessed the potential effect of differences in baseline disease stage through subgroup analysis, which showed that the results observed in patients with stage III/IV disease were consistent with the analyses that included all disease stages. A thorough exploration of $B R A F$ mutation status was precluded by a lack of reporting in all but three studies.

Among the approved treatment options at the time of this analysis, pembrolizumab had the shortest follow-up duration. The pembrolizumab arm of KEYNOTE-054 had only 25 patients at risk at 27 months and 3 patients at risk at 30 months [28], whereas the nivolumab arm of CheckMate 238 had 249 patients at risk at 27 months and 243 patients at risk at 30 months [40]. The shorter duration of follow-up may have created biased estimates in the time-varying HRs.

Treatment effect was assessed using both constant and time-varying HRs to identify differences between the treatments. Time-dependent and constant HRs for RFS were similar in comparisons between nivolumab and ipilimumab and between nivolumab and pembrolizumab (immunotherapies), but comparisons were more complex when evaluating nivolumab versus dabrafenib plus trametinib (targeted therapy). Both the constant HR for RFS over the entire follow-up period and the time-varying HR for RFS at 12 months showed that the risk of recurrence with nivolumab was similar to that with dabrafenib plus trametinib. However, HRs at 24, 36, and 48 months indicated a higher reduction in the risk of recurrence with nivolumab than with dabrafenib plus trametinib as adjuvant treatment. On the basis of these analyses, compared with targeted therapies, the treatment effect with nivolumab appears to be durable, with a potential for

Table 5 Time-varying HR estimates ${ }^{a}$ from a fixed-effects NMA for DMFS ( 1 1 =0, p2 = -0.5, scale, shape $\left.\times 1\right)$ in patients with stage II-IV melanoma

\begin{tabular}{lllll}
\hline Treatment & Time points & & & \\
\cline { 2 - 5 } & $\mathbf{1 2}$ months & $\mathbf{2 4}$ months & 36 months & 48 months \\
\hline NIVO vs. OBS/PBO & $\mathbf{0 . 6 7}(\mathbf{0 . 4 8 - 0 . 9 3 )}$ & $0.77(0.50-1.20)$ & $0.83(0.46-1.49)$ & $0.87(0.42-1.76)$ \\
NIVO vs. DAB+TRAM & $1.06(0.68-1.63)$ & $0.65(0.37-1.14)$ & $0.51(0.24-1.07)$ & $0.44(0.17-1.08)$ \\
NIVO vs. IPI (10 mg/kg) & $0.80(0.61-1.06)$ & $0.88(0.60-1.28)$ & $0.93(0.55-1.56)$ & $0.96(0.50-1.84)$ \\
NIVO vs. IFN & $0.73(0.51-1.05)$ & $0.80(0.51-1.27)$ & $0.84(0.47-1.53)$ & $0.86(0.42-1.78)$ \\
\hline
\end{tabular}

${ }^{a}$ The value in each cell represents the hazard ratio (95\% credible interval) for the comparison of the treatments; bolded values are statistically significant at the 0.05 significance level

$D A B$ dabrafenib, DMFS distant metastasis-free survival, $H R$ hazard ratio, IFN interferon, IPI ipilimumab, NIVO nivolumab, NMA network meta-analysis, $O B S$ observation, $P B O$ placebo, TRAM trametinib 
lower risk of recurrence over the long term, which may be an important consideration in informing treatment choice.

The current study highlights the overall safety risks among the different adjuvant treatment options. The odds of experiencing grade $3 / 4$ AEs were lower with nivolumab than with the other treatments. However, this analysis did not take into account the type of AEs or the time to resolution of specific AEs (eg, immune-mediated AEs associated with immunotherapies versus treatment-related AEs associated with targeted therapies).

Development of the current work was based on similar NMA studies that were published recently $[18,19]$. As in our analysis, one study presented an SLR and an NMA that showed similar efficacy between dabrafenib plus trametinib and nivolumab using a constant HR over time [18]; however, this analysis did not include a time-varying $\mathrm{HR}$, which was incorporated into the current study. In another NMA study, a time-varying HR analysis was conducted, but nivolumab was excluded as a comparator because of differences in the duration of ipilimumab treatment in the CheckMate 238 (1 year) and EORTC 18071 (3 years) trials [19], which were included in the current study. Although the majority of recent trials have administered adjuvant treatment for 1 year, treatment duration is unlikely to influence time-varying HRs. Moreover, the median number of ipilimumab doses was four in the EORTC 18071 study, and only a few patients received ipilimumab beyond 1 year.

\section{Conclusions}

In summary, nivolumab is an adjuvant treatment option with a promising risk-benefit profile indicated for the treatment of patients with resected melanoma. This study provides comparative evidence for nivolumab versus other adjuvant treatment options, as well as placebo. The efficacy assessment reported here may support patient preferences and clinician choices for short-term versus longterm effectiveness. The current analysis is consistent with the established safety profile of nivolumab. Due to the potential occurrence of immune-mediated AEs, additional analyses may be warranted, such as long-term follow-up of safety data.

\section{Supplementary information}

Supplementary information accompanies this paper at https://doi.org/10. 1186/s12885-020-07538-1.

Additional file 1: Appendix A. Systematic literature review details and results. Figure A.1. Study selection flow diagram of updated SLR (May 2019). Table A.1. Study selection criteria to identify trials for the systematic literature review. Table A.2. Search strategy for EMBASE (EMBASE 1974 to October 11, 2017; Search executed: October 12, 2017). Table A.3. Search strategy for MEDLINE (Ovid MEDLINE(R) In-Process \&
Other Non-Indexed Citations, Ovid MEDLINE(R) Daily and Ovid MEDLINE(R) 1946 to Present; Search executed: October 12, 2017). Table A.4. Search strategy for Cochrane Register of Controlled Trials (Cochrane Register of Controlled Trials September 2017; Search executed: October 12, 2017). Table A.5. Search strategy for EMBASE (EMBASE 1974 to 2018 May 07; Search executed: May 8, 2018). Table A.6. Search strategy for MEDLINE (Ovid MEDLINE(R) In-Process \& Other Non-Indexed Citations, Ovid MEDLINE(R) Daily and Ovid MEDLINE(R) 1946 to Present; Search executed: May 8, 2018). Table A.7. Search strategy for Cochrane Register of Controlled Trials (Cochrane Register of Controlled Trials March 2018; Search executed: May 8, 2018). Table A.8. Search strategy for EMBASE (EMBASE 1974 to 2019 April 30; Search executed: May 1, 2019). Table A.9. Search strategy for MEDLINE (Ovid MEDLINE(R) In-Process \& Other Non-Indexed Citations, Ovid MEDLINE(R) Daily and Ovid MEDLINE(R) 1946 to Present; Search executed: May 1, 2019). Table A.10. Search strategy for Cochrane Register of Controlled Trials (Cochrane Register of Controlled Trials April 2019; Search executed: May 1, 2019). Table A.11. Patient characteristics in randomized controlled trials included in network meta-analyses. Table A.12. Cochrane risk of bias assessment of randomized controlled trials included in the feasibility assessment. Table A.13. Safety data from randomized controlled trials included in the feasibility assessment

Additional file 2: Appendix B. Consistency checks. Table B.1. Assessment of consistency; full analysis set, all studies

Additional file 3: Appendix C. Results of the stage III/IV subgroup analyses. Table C.1. Stage III/IV population - constant hazard ratios estimated from fixed-effects network meta-analysis for recurrence-free/ disease-free survival. Table C.2. Stage III/IV population - constant hazard ratios estimated from fixed-effects network meta-analysis for distant metastasis-free survival

Additional file 4: Appendix D. Safety analyses. Figure D.1. Network diagrams of randomized controlled trials for subgroup. Table D.1. Stage II/IIIIV population - odds ratios estimated from fixed-effects network meta-analysis for grade $3 / 4$ adverse events analysis of safety outcomes. Table D.2. Stage II/III/IV population - odds ratios estimated from fixedeffects network meta-analysis for discontinuations due to adverse events. Table D.3. Stage II/II//IV population - odds ratios estimated from fixedeffects network meta-analysis for discontinuations

\section{Abbreviations}

AE: Adverse event; Crl: Credible interval; DFS: Disease-free survival; DMFS: Distant metastasis-free survival; FDA: Food and Drug Administration; HR: Hazard ratio; IFN: Interferon; KM: Kaplan-Meier; NMA: Network metaanalysis; PD: Programmed death; RCT: Randomized controlled trial; RFS: Recurrence-free survival; SLR: Systematic literature review

\section{Acknowledgements}

The authors would like to thank the patients and families who made the trials included in these analyses possible and the clinical study teams who participated in the trials. Medical writing assistance was provided by Michael Zoratti, MSc of Zoratti HEOR Consulting Inc. Editorial assistance was provided by Kakoli Parai, PhD, and Andrea Lockett of Ashfield Healthcare

Communications, funded by Bristol Myers Squibb. We would also like to thank Bagirathy Ravishankar of Bristol Myers Squibb for overall support for this manuscript.

\section{Authors' contributions}

$K T, K C, A A, A M$, and SK contributed to the conception or design of this study. $K T$ and $K C$ were involved in data acquisition and analysis. KT, MRM, KC, $\mathrm{AA}, \mathrm{AM}$, and SK participated in data interpretation, read, and approved the manuscript.

\section{Funding}

This study was funded by Bristol Myers Squibb. Precision HEOR received funding from Bristol Myers Squibb for their involvement in the design of the study, data acquisition and analysis, and development of the manuscript. The Bristol Myers Squibb employees who served as authors contributed to the design of the study, interpretation of data, and writing of the manuscript. 


\section{Availability of data and materials}

All data generated or analyzed during this study are included in this published article and its supplementary information files. The Bristol Myers Squibb policy on data sharing may be found at https://www.bms.com/ researchers-and-partners/independent-research/data-sharing-request-process. html.

\section{Ethics approval and consent to participate} Not applicable.

\section{Consent for publication}

Not applicable.

\section{Competing interests}

KT and KC are employees of Precision HEOR, which received funding from Bristol Myers Squibb for the current work. MRM has served as an advisor to Amgen, Array Biopharma, BiolineRx, Bristol Myers Squibb, GlaxoSmithKline, Immunocore, Kineta, Novartis, Rigontec, Roche, and Silicon Therapeutics; has received institutional research support from Array Biopharma, AstraZeneca, BiolineRx, Bristol Myers Squibb, Eisai, GlaxoSmithKline, Immunocore, Merck, Merck Sharp \& Dohme, Millenium, Novartis, Pfizer, Regeneron, Replimune, Rigontec, and Roche; has received travel support from Immunocore, Merck, Merck Sharp \& Dohme, and Replimune; and is a member of an independent data safety monitoring committee for Eisai and Merck/Merck Sharp \& Dohme. AA and AM are employees of and stockholders in Bristol Myers Squibb. SK is an employee of Bristol Myers Squibb.

\section{Author details}

${ }^{1}$ Precision HEOR, 1505 West 2nd Avenue, Vancouver, BC V6H 3Y4, Canada. 2University of Oxford, Old Road Campus Research Building, Roosevelt Drive, Oxford OX3 7DQ, UK. ${ }^{3}$ Bristol Myers Squibb, Unit 2 Uxbridge Business Park, Uxbridge UB8 1DH, UK. ${ }^{4}$ Bristol Myers Squibb, Route 206 and Province Line Road, Princeton, NJ 08543, USA.

\section{Received: 2 July 2020 Accepted: 16 October 2020}

\section{Published online: 05 January 2021}

\section{References}

1. Pasquali S, Hadjinicolaou AV, Chiarion Sileni V, Rossi CR, Mocellin S. Systemic treatments for metastatic cutaneous melanoma. Cochrane Database Syst Rev. 2018;2:CD011123. https://doi.org/10.1002/14651858.CD011123.pub2.

2. Garbe C, Eigentler TK, Keilholz U, Hauschild A, Kirkwood JM. Systematic review of medical treatment in melanoma: current status and future prospects. Oncologist. 2011;16:5-24. https://doi.org/10.1634/theoncologist.2010-0190.

3. Molife R, Hancock BW. Adjuvant therapy of malignant melanoma. Crit Rev Oncol Hematol. 2002:44:81-102.

4. National Comprehensive Cancer Network. NCCN Clinical Practice Guidelines in Oncology (NCCN Guidelines ${ }^{\circledR}$ ): Cutaneous Melanoma. Version 2.2020. 2019. https://www.nccn.org/professionals/physician_gls/pdf/cutaneous_ melanoma.pdf. Accessed 9 Apr 2020.

5. Coit DG, Thompson JA, Albertini MR, Barker C, Carson WE, Contreras C, et al. Cutaneous melanoma, version 2.2019, NCCN clinical practice guidelines in oncology. J Natl Compr Cancer Netw. 2019;17:367-402.

6. Dummer R, Hauschild A, Lindenblatt N, Pentheroudakis G, Keilholz U, ESMO guidelines committee. Cutaneous melanoma: ESMO clinical practice guidelines for diagnosis, treatment and follow-up. Ann Oncol. 2015;26(Suppl 5):v126-32. https://doi.org/10.1093/annonc/mdv297.

7. Hauschild A, Dummer R, Schadendorf D, Santinami M, Atkinson V, Mandalà $M$, et al. Longer follow-up confirms relapse-free survival benefit with adjuvant dabrafenib plus trametinib in patients with resected BRAF V600mutant stage III melanoma. J Clin Oncol. 2018;36:3441-9. https://doi.org/10. 1200/JCO.18.01219.

8. Eggermont AMM, Blank CU, Mandala M, Long GV, Atkinson VG, Dalle S, et al. Prognostic and predictive value of AJCC-8 staging in the phase III EORTC1325/KEYNOTE-054 trial of pembrolizumab vs placebo in resected high-risk stage III melanoma. Eur J Cancer. 2019;116:148-57.

9. Eggermont AMM, Chiarion-Sileni V, Grob JJ, Dummer R, Wolchok JD, Schmidt $H$, et al. Adjuvant ipilimumab versus placebo after complete resection of stage III melanoma: long-term follow-up results of the European Organisation for Research and Treatment of Cancer 18071 double-blind phase 3 randomised trial. Eur J Cancer. 2019;119:1-10.
10. Kirkwood JM, Strawderman MH, Ernstoff MS, Smith TJ, Borden EC, Blum RH. Interferon alfa-2b adjuvant therapy of high-risk resected cutaneous melanoma: the eastern cooperative oncology group trial EST 1684. J Clin Oncol. 1996;14:7-17.

11. US Food and Drug Administration. Yervoy (ipilimumab). 2018. https://www. accessdata.fda.gov/drugsatfda_docs/label/2018/125377s094/bl.pdf. Accessed 30 Sept 2019.

12. US Food and Drug Administration. Opdivo (nivolumab). 2018. https://www. accessdata.fda.gov/drugsatfda_docs/label/2018/125554s058lbl.pdf. Accessed 30 Sept 2019.

13. US Food and Drug Administration. Keytruda (pembrolizumab). 2018. https:// www.accessdata.fda.gov/drugsatfda_docs/label/2018/125514s034lbl.pdf. Accessed 30 Sept 2019.

14. FDA approves dabrafenib plus trametinib for adjuvant treatment of melanoma with BRAF V600E or V600K mutations. US Food and Drug Administration website. 2018. https://www.fda.gov/drugs/resources-information-approveddrugs/fda-approves-dabrafenib-plus-trametinib-adjuvant-treatment-melanomabraf-v600e-or-v600k-mutations. Accessed 30 Sept 2019.

15. Weber J, Mandala M, Del Vecchio M, Gogas HJ, Arance AM, Cowey CL, et al. Adjuvant nivolumab versus ipilimumab in resected stage III or IV melanoma. N Engl J Med. 2017;377:1824-35. https://doi.org/10.1056/NEJMoa1709030.

16. Dias S, Welton NJ, Sutton AJ, Caldwell DM, Lu G, Ades AE. Evidence synthesis for decision making 4: inconsistency in networks of evidence based on randomized controlled trials. Med Decis Mak. 2013;33:641-56. https://doi.org/10.1177/0272989X12455847.

17. Jansen JP, Naci H. Is network meta-analysis as valid as standard pairwise meta-analysis? It all depends on the distribution of effect modifiers. BMC Med. 2013;11:159. https://doi.org/10.1186/1741-7015-11-159.

18. Sharma R, Koruth R, Kanters S, Druyts E, Tarhini A. Comparative efficacy and safety of dabrafenib in combination with trametinib versus competing adjuvant therapies for high-risk melanoma. J Comp Eff Res. 2019;8:1349-63.

19. Lorenzi M, Arndorfer S, Aguiar-Ibañez R, Scherrer E, Liu FX, Krepler C. An indirect treatment comparison of the efficacy of pembrolizumab versus competing regimens for the adjuvant treatment of stage III melanoma. J Drug Assess. 2019;8:135-45.

20. Jansen JP. Network meta-analysis of survival data with fractional polynomials. BMC Med Res Methodol. 2011;11:61. https:/doi.org/10.1186/1471-2288-11-61.

21. Ouwens MJNM, Philips Z, Jansen JP. Network meta-analysis of parametric survival curves. Res Synth Methods. 2011;1:258-71. https:// doi.org/10.1002/jrsm.25.

22. Agarwala SS, Lee SJ, Yip W, Rao UN, Tarhini AA, Cohen Gl, et al. Phase II randomized study of 4 weeks of high-dose interferon- $a-2 b$ in stage T2bNO, T3a-bNO, T4a-bNO, and T1-4N1a-2a (microscopic) melanoma: a trial of the eastern cooperative oncology group-American College of Radiology Imaging Network cancer research group (E1697). J Clin Oncol. 2017;35:88592. https://doi.org/10.1200/JCO.2016.70.2951.

23. Cameron DA, Cornbleet MC, Mackie RM, Hunter JA, Gore M, Hancock B, Scottish Melanoma Group, et al. Adjuvant interferon alpha $2 \mathrm{~b}$ in high risk melanoma - the Scottish study. Br J Cancer. 2001;84:1146-9.

24. Cascinelli N, Belli F, MacKie RM, Santinami M, Bufalino R, Morabito A. Effect of long-term adjuvant therapy with interferon alpha-2a in patients with regional node metastases from cutaneous melanoma: a randomised trial. Lancet. 2001;358:866-9.

25. Eggermont AM, Chiarion-Sileni V, Grob JJ, Dummer R, Wolchok JD, Schmidt $\mathrm{H}$, et al. Adjuvant ipilimumab versus placebo after complete resection of high-risk stage III melanoma (EORTC 18071): a randomised, double-blind, phase 3 trial. Lancet Oncol. 2015;16:522-30. https://doi.org/10.1016/S14702045(15)70122-1.

26. Eggermont AM, Suciu S, MacKie R, Ruka W, Testori A, Kruit W, EORTC Melanoma Group, et al. Post-surgery adjuvant therapy with intermediate doses of interferon alfa $2 \mathrm{~b}$ versus observation in patients with stage $\mathrm{llb} / \mathrm{b} / \mathrm{l}$ melanoma (EORTC 18952): randomised controlled trial. Lancet. 2005;366:1189-96.

27. Eggermont AM, Suciu S, Santinami M, Testori A, Kruit WH, Marsden J, EORTC Melanoma Group, et al. Adjuvant therapy with pegylated interferon alfa-2b versus observation alone in resected stage III melanoma: final results of EORTC 18991, a randomised phase III trial. Lancet. 2008;372:117-26. https:// doi.org/10.1016/S0140-6736(08)61033-8.

28. European Medicines Agency. Keytruda: European Public Assessment Report (EPAR) - Product Information. 2019. https://www.ema.europa.eu/en/ documents/product-information/keytruda-epar-product-information_en.pdf. Accessed 30 Sept 2019. 
29. Eggermont AMM, Blank CU, Mandala M, Long GV, Atkinson V, Dalle S, et al. Adjuvant pembrolizumab versus placebo in resected stage III melanoma. N Engl J Med. 2018;378:1789-801.

30. Flaherty LE, Othus M, Atkins MB, Tuthill RJ, Thompson JA, Vetto JT, et al. Southwest oncology group S0008: a phase III trial of high-dose interferon alfa- $2 \mathrm{~b}$ versus cisplatin, vinblastine, and dacarbazine, plus interleukin-2 and interferon in patients with high-risk melanoma-an intergroup study of cancer and leukemia group B, Children's oncology group, eastern cooperative oncology group, and southwest oncology group. J Clin Oncol. 2014;32:3771-8. https://doi.org/10.1200/JCO.2013.53.1590

31. Garbe C, Radny P, Linse R, Dummer R, Gutzmer R, Ulrich J, et al. Adjuvant low-dose interferon a2a with or without dacarbazine compared with surgery alone: a prospective-randomized phase III DeCOG trial in melanoma patients with regional lymph node metastasis. Ann Oncol. 2008;19:1195201. https://doi.org/10.1093/annonc/mdn001.

32. Hancock BW, Wheatley K, Harris S, Ives N, Harrison G, Horsman JM, et al. Adjuvant interferon in high-risk melanoma: the AIM HIGH study-United Kingdom coordinating committee on cancer research randomized study of adjuvant low-dose extended-duration interferon alfa-2a in high-risk resected malignant melanoma. J Clin Oncol. 2004;22:53-61.

33. Hansson J, Aamdal S, Bastholt L, Brandberg Y, Hernberg M, Nilsson B, Nordic Melanoma Cooperative Group, et al. Two different durations of adjuvant therapy with intermediate-dose interferon alfa-2b in patients with high-risk melanoma (Nordic IFN trial): a randomised phase 3 trial. Lancet Oncol. 2011; 12:144-52. https://doi.org/10.1016/S1470-2045(10)70288-6.

34. Kim KB, Legha SS, Gonzalez R, Anderson CM, Johnson MM, Liu P, et al. A randomized phase III trial of biochemotherapy versus interferon-alpha- $2 \mathrm{~b}$ for adjuvant therapy in patients at high risk for melanoma recurrence. Melanoma Res. 2009;19:42-9. https://doi.org/10.1097/CMR.0b013e328314b84a.

35. Kirkwood JM, Ibrahim JG, Sondak VK, Richards J, Flaherty LE, Ernstoff MS, et al High- and low-dose interferon alfa-2b in high-risk melanoma: first analysis of intergroup trial E1690/S9111/C9190. J Clin Oncol. 2000;18:2444-58.

36. Kleeberg UR, Suciu S, Bröcker EB, Ruiter DJ, Chartier C, Lienard D, EORTC Melanoma Group in cooperation with the German Cancer Society (DKG), et al. Final results of the EORTC 18871/DKG 80-1 randomised phase III trial: IIFN-alpha2b versus rIFN-gamma versus ISCADOR M versus observation after surgery in melanoma patients with either high-risk primary (thickness $>3$ $\mathrm{mm}$ ) or regional lymph node metastasis. Eur J Cancer. 2004;40:390-402.

37. Long GV, Hauschild A, Santinami M, Atkinson V, Mandalà M, Chiarion-Sileni V, et al. Adjuvant dabrafenib plus trametinib in stage III BRAF-mutated melanoma. N Engl J Med. 2017;377:1813-23. https://doi.org/10.1056/NEJMoa1708539.

38. Stadler R, Luger T, Bieber T, Köhler U, Linse R, Technau K, et al. Long-term survival benefit after adjuvant treatment of cutaneous melanoma with dacarbazine and low dose natural interferon alpha: a controlled, randomised multicentre trial. Acta Oncol. 2006;45:389-99.

39. Tarhini AA, Lee SJ, Hodi FS, Rao UNM, Cohen Gl, Hamid O, et al. A phase III randomized study of adjuvant ipilimumab (3 or $10 \mathrm{mg} / \mathrm{kg}$ ) versus high-dose interferon alfa-2b for resected high-risk melanoma (U.S. Intergroup E1609): preliminary safety and efficacy of the ipilimumab arms. J Clin Oncol. 2017; 35(Suppl) Abstract 9500. https://doi.org/10.1200/JCO.2017.35.15_suppl.9500.

40. Weber J, Del Vecchio M, Mandala M, Gogas HJ, Arance AM, Dalle S, et al. Adjuvant nivolumab versus ipilimumab in resected stage III/IV melanoma: 3-year efficacy and biomarker results from the phase 3 CheckMate 238 trial. Presented at ESMO 2019; 27 Sept-1 Oct 2019; Barcelona, Spain.

41. Eigentler TK, Gutzmer R, Hauschild A, Heinzerling L, Schadendorf D, Nashan D, Dermatologic Cooperative Oncology Group (DeCOG), et al. Adjuvant treatment with pegylated interferon a-2a versus low-dose interferon $a-2 a$ in patients with high-risk melanoma: a randomized phase III DeCOG trial. Ann Oncol. 2016;27:1625-32. https://doi.org/10.1093/annonc/mdw225.

42. Grob JJ, Jouary T, Dréno B, Asselineau J, Gutzmer R, Hauschild A, et al. Adjuvant therapy with pegylated interferon alfa-2b (36 months) versus lowdose interferon alfa-2b (18 months) in melanoma patients without macrometastatic nodes: an open-label, randomised, phase 3 European Association for Dermato-Oncology (EADO) study. Eur J Cancer. 2013;49:16674. https://doi.org/10.1016/j.ejca.2012.07.018.

43. Lian B, Si L, Cui C, Chi Z, Sheng X, Mao L, et al. Phase II randomized trial comparing high-dose IFN- $a 2 b$ with temozolomide plus cisplatin as systemic adjuvant therapy for resected mucosal melanoma. Clin Cancer Res. 2013;19: 4488-98. https://doi.org/10.1158/1078-0432.CCR-13-0739.

44. McMasters KM, Egger ME, Edwards MJ, Ross MI, Reintgen DS, Noyes RD, et al. Final results of the sunbelt melanoma trial: a multi-institutional prospective randomized phase III study evaluating the role of adjuvant high-dose interferon alfa-2b and completion lymph node dissection for patients staged by sentinel lymph node biopsy. J Clin Oncol. 2016;34:107986. https://doi.org/10.1200/JCO.2015.63.3776.

45. Mohr P, Hauschild A, Trefzer U, Enk A, Tilgen W, Loquai C, et al. Intermittent high-dose intravenous interferon alfa-2b for adjuvant treatment of stage III melanoma: final analysis of a randomized phase III dermatologic cooperative oncology group trial. J Clin Oncol. 2015;33:4077-84. https://doi. org/10.1200/JCO.2014.59.6932.

46. Tobin RP, Jordan KR, Robinson WA, Davis D, Borges VF, Gonzalez R, et al. Targeting myeloid-derived suppressor cells using all-trans retinoic acid in melanoma patients treated with Ipilimumab. Int Immunopharmacol. 2018; 63:282-91. https://doi.org/10.1016/j.intimp.2018.08.007.

47. Wang X, Mao LL, Si L, Chi Z, Cui C, Nan X, et al. Efficacy of high-dose adjuvant interferon therapy in high-risk melanoma harboring gene mutations. J Clin Oncol. 2015;33(Suppl) Abstract 9047. https://doi.org/10. 1200/jco.2015.33.15_suppl.9047.

\section{Publisher's Note}

Springer Nature remains neutral with regard to jurisdictional claims in published maps and institutional affiliations.

\section{Ready to submit your research? Choose BMC and benefit from:}

- fast, convenient online submission

- thorough peer review by experienced researchers in your field

- rapid publication on acceptance

- support for research data, including large and complex data types

- gold Open Access which fosters wider collaboration and increased citations

- maximum visibility for your research: over $100 \mathrm{M}$ website views per year

At BMC, research is always in progress.

Learn more biomedcentral.com/submissions 